\title{
Topographical distribution and characterization of epithelial cells and intraepithelial lymphocytes in the human ocular mucosa
}

\author{
$\mathrm{R}_{\text {Reinoso }}{ }^{1,2}, \mathrm{R}_{\text {Martín-Sanz }}^{1}, \mathrm{M} \mathrm{Martino}^{1,2}$, ME Mateo $^{1}, \mathrm{R}_{\text {Blanco-Salado }}^{3}, \mathrm{M} \mathrm{Calonge}^{1,2}$ \\ and A Corell ${ }^{1-3}$
}

The conjunctiva plays a key role in the protection of the ocular surface by initiating and regulating immune responses. In this study, we analyze the relative proportion of intraepithelial lymphocytes (IELs), apoptotic cells, and proliferative state in three different topographical regions of the normal human conjunctiva. Superior tarsal, superior bulbar, and inferior tarsal-bulbar-fornical conjunctival cells were collected by brush cytology from 63 healthy donors. Flow cytometry analysis showed higher levels of $\mathrm{CD}^{+}$and $\mathrm{CD} 8^{+}$IELs in both upper tarsal and bulbar conjunctiva than in the inferior tarsal-bulbar-fornix, where the $\mathrm{CD} 19^{+} \mathrm{B}$ cells were increased. For all zones two different cell populations (by cell size and complexity) were present in the apoptosis assay. The more complex cells were reduced within the inferior tarsal-bulbar-fornix when compared with the superior bulbar and tarsal areas. Less complex cells were more predominant in the inferior conjunctiva and were mainly alive. The mean proliferation index of the conjunctival epithelium was significantly lower in the superior bulbar conjunctiva than in superior tarsal and inferior fornical conjunctivas. These findings suggest that each topographical zone from normal human conjunctiva has a unique profile of immunophenotype, viability, and proliferative state that could be related to a differentiated regional functionality.

\section{INTRODUCTION}

The conjunctiva is a thin mucous membrane that extends from the eyelid margin to the corneoscleral limbus. It forms a physical protective barrier that prevents the entrance of extraneous matter into the ocular globe. Unlike the cornea, the epithelium is underlain by a loose vascularized connective tissue, which is attached to the epithelium by a basement membrane. As a mucosal surface, the conjunctiva is equipped with a diverse array of innate defense mechanisms, including anti-microbial peptides, macrophages, mast cells, and neutrophils that prevent pathogen invasion and maintain mucosal integrity. ${ }^{1-4}$ It is increasingly recognized that the conjunctiva is also provided with specific immune response cells, $\mathrm{T}$ and $\mathrm{B}$ lymphocytes, as they occur in other mucosal epithelia. This structural arrangement is referred to as a conjunctiva-associated lymphoid tissue (CALT) and is composed of both organized and diffuse components. ${ }^{5-8}$ Previous reports have shown that organized lymphoid follicles reside mainly in the tarsal conjunctiva, diminishing towards the fornix and further towards the bulbar conjunctiva, where they are rarely seen. ${ }^{9}$ However, there is little information regarding the topographical distribution of the diffusely scattered intraepithelial lymphocytes (IELs) in the normal human conjunctiva.

Homeostasis of the conjunctival epithelial cellular composition plays a critical role for maintaining the physiological and immunological integrity of the ocular surface. This is achieved by a delicate balance between apoptosis and cell proliferation. Earlier studies in normal subjects showed a strong expression of apoptotic markers and apoptosis-related genes by conjunctival epithelial cells. ${ }^{10-14}$ Using surgical biopsies, Tan et al. ${ }^{15}$ demonstrated that apoptotic cells are scattered throughout the whole epithelium of normal conjunctiva. Similarly, Pellegrini et al. ${ }^{16}$ reported that bulbar and fornical conjunctival cells have an equivalent in vitro proliferative capacity, suggesting that human conjunctival epithelial stem cells might be evenly distributed within these two zones. However, there have been no

\footnotetext{
${ }^{1}$ Ocular Surface Group, Institute for Applied Ophthalmobiology (IOBA), University of Valladolid, Valladolid, Spain. ${ }^{2}$ Networking Research Center on Bioengineering, Biomaterials and Nanomedicine (CIBER-BBN), Valladolid, Spain. ${ }^{3}$ Department of Immunology, University of Valladolid, Valladolid, Spain. Correspondence: A Corell (acorell@ped.uva.es) 


\section{ARTICLES}
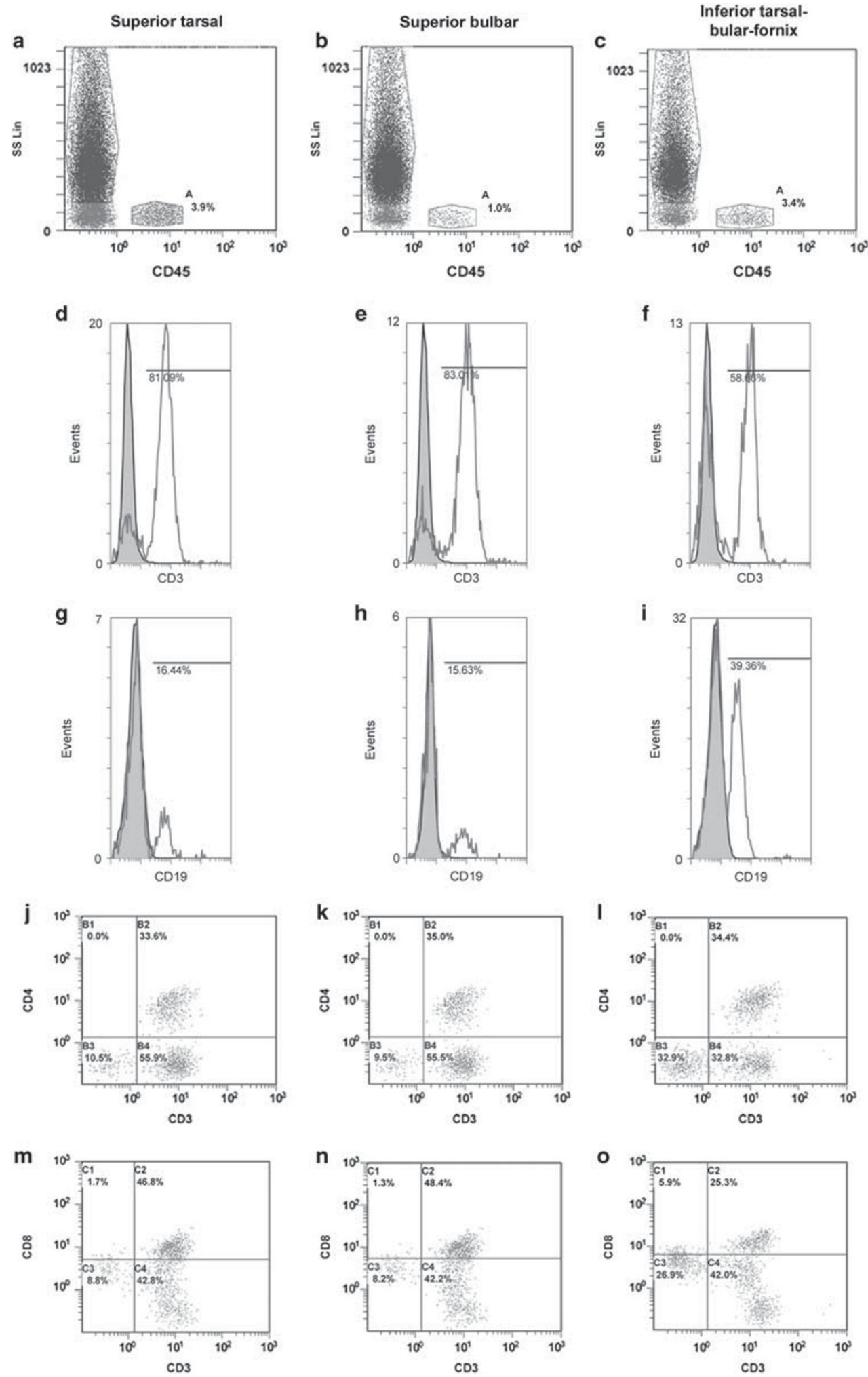

Figure 1 Immunophenotypic analysis from representative cases at the three different topographical regions of the normal human conjunctiva. Leukocytes (gate A), epithelial cells, and cellular debris. (a-c) Side scatter (SS) vs. CD45 dot plot showed the lymphocyte population (CD45 ${ }^{+}$and low cellular complexity, SS) that was gated for analysis (gate A). (d-f) Fluorescence histogram of CD3-PC5 gated on CD45+ cells showed a CD3 ${ }^{+}$ T-lymphocyte population (segment). (g-i) Fluorescence histogram of CD19-PC5 gated on CD45 ${ }^{+}$cells showed a CD19+ B-lymphocyte population (segment). (j-I) CD3 vs. CD4 dot plot gated on $\mathrm{CD}^{+}$cells showed a CD3 ${ }^{+} \mathrm{CD} 4^{+}$T-helper lymphocyte population (region $\left.\mathrm{B} 2\right)$. ( $\left.\mathbf{m}-\mathbf{0}\right) \mathrm{CD} 3 \mathrm{vs.} \mathrm{CD} 8 \mathrm{dot}$ plot gated on $\mathrm{CD}^{+}$cells showed a $\mathrm{CD} 3^{+} \mathrm{CD} 8^{+} \mathrm{T}$-cytotoxic lymphocyte population (region $\mathrm{C} 2$ ). PC5, phycoerythrin-cyanine 5 .

The color reproduction of this figure is available on the Mucosal Immunology journal online. 
detailed studies to date that determine exactly the conjunctival region with the highest levels of apoptosis and proliferation.

In this study, we examined the superior tarsal, superior bulbar, and inferior tarsal-bulbar-fornical conjunctivas of healthy donors to assess the topographical distribution of IEL subtypes $\mathrm{T}, \mathrm{B}$, and NK cells. We also determined the differential levels of apoptosis and cell proliferation in those regions. Finally, we analyzed by in vivo confocal microscopy the morphology of human superior bulbar and tarsal conjunctivas before and after sample collection to detect possible differences between the two regions and changes in the epithelium as a result of cell collection by brush cytology (BC).

\section{RESULTS}

\section{Flow cytometry}

Different ratios of IEL subtypes detected within distinct conjunctival zones. On the basis of the forward scatter (FS) vs. side scatter (SS) dot plots of the flow cytometry data, the vast majority (>95\%) of the BC-recovered conjunctival cells were of epithelial origin. However, by using the positive CD45 staining and low SS signal, which detects cellular complexity or cytoplasmic granularity, a small population of IELs was also detected. There were significantly $(P<0.001)$ fewer $\mathrm{CD} 45^{+}$IELs in superior bulbar conjunctiva $(0.51 \pm 0.30 \%)$ compared with superior tarsal and inferior tarsal-bulbar-fornical regions $(4.11 \pm 3.11 \%$ and $3.74 \pm 2.53 \%$ respectively; Figure 1a-c). Immunophenotypic analysis of IELs revealed that most of these lymphocytes were $\mathrm{CD}^{+} \mathrm{T}$ cells, followed by $\mathrm{CD} 19^{+} \mathrm{B}$ lymphocytes and residual $\mathrm{CD} 3{ }^{-} \mathrm{CD} 16^{+} / \mathrm{CD} 56^{+} \mathrm{NK}$ lymphocytes (Figure 2a). Both superior tarsal and superior bulbar conjunctivas had significantly $(P<0.001)$ more $\mathrm{CD}^{+} \mathrm{T}$ cells (Figure $\left.\mathbf{1 d}-\mathbf{f}\right)$ and less $\mathrm{CD} 19^{+} \mathrm{B}$ cells (Figure 1g-i) than inferior tarsal-bulbar-fornix (Figure 2a). Consequently, the $\mathrm{CD} 3 / \mathrm{CD} 19$ ratio was significantly $(P<0.001)$ lower in the inferior fornix than in either of the upper conjunctival regions (Figure 2b). There were no significant differences among these populations between the upper tarsal and bulbar conjunctival areas (Figure 2b). When $\mathrm{CD}^{+} \mathrm{T}$ cells subtypes were analyzed, the inferior tarsal-bulbar-fornical region had significantly $(P<0.001)$ less $\mathrm{CD}^{+}$ $\mathrm{T}$ cells and therefore higher $\mathrm{CD} 4 / \mathrm{CD} 8$ ratio $(2.43 \pm 1.47 \%$; $P<0.01)$ than the superior tarsal and superior bulbar regions $(0.97 \pm 0.38 \%$ and $0.86 \pm 0.38 \%$, respectively). These showed predominance of $\mathrm{CD}^{+}{ }^{+}$over $\mathrm{CD} 4{ }^{+} \mathrm{T}$ cells (Figures $\mathbf{1 j}-\mathbf{o}$ and $\mathbf{2}$ ).

Variation in viability between cell types in different conjunctival regions. In the three conjunctival zones, two distinct cell populations based upon cell size (FS scale) and complexity (SS scale) were differentiated in the apoptosis assay (Figure 3a-c). Most of the BC-recovered cells were larger, more complex, with heterogeneous complexity and had poor viability. The remainder was composed of smaller, less complex cells, with higher viability. The smallest proportion of the more complex cells, $54.39 \pm 16.98 \%$, was present in the inferior tarsal-bulbar-fornical region $(P<0.001$; Figure 4a). There were no significant differences in the percents of early apoptotic or late apoptotic cells among more complex cells in the three regions; however, the percent of dead cells in the superior bulbar region (15.23 $\pm 7.26 \%$; Figures $3 \mathbf{d}-\mathbf{f}$ and $\mathbf{4 a}$ ) was significantly higher than in the superior tarsal $(9.33 \pm 8.25 \% ; P<0.05)$ and inferior tarsal-bulbar-fornical $(5.05 \pm 3.33 \% ; P<0.001)$ areas. The superior tarsal zone had the highest percentage of complex apoptotic cells and the lowest viability compared with the other conjunctival areas.

In the smaller and less complex population, cell viability was significantly higher in the inferior tarsal-bulbar-fornical region, $93.18 \pm 4.66 \%$ than in the upper tarsal and bulbar conjunctivas $(72.83 \pm 11.37 \%$ and $63.13 \pm 15.95 \%$ respectively, $P<0.001$, Figures $\mathbf{3 g}-\mathbf{i}$ and $\mathbf{4 b}$ ). The superior bulbar area had the highest levels of early apoptotic and dead cells, $32.28 \pm 14.68 \%$ and $1.36 \pm 1.08 \%$, respectively, within the smaller, less complex cells $(P<0.001$; Figure 4b). The superior tarsal zone reported the highest percentage of late apoptotic cells within this cell population, $4.23 \pm 2.92 \%(P<0.01$; Figure $4 \mathbf{b})$.

Comparison of cell cycle phases among different conjunctival zones. In the superior bulbar region, $82.40 \pm 4.63 \%$ of the cells were in the $G_{0} / G_{1}$ phases of the cell cycle (resting or pre-cycling), which was significantly $(P<0.01)$ higher than in the superior tarsal and inferior tarsal-bulbar-fornical areas $(75.46 \pm 7.08 \%$ and $75.59 \pm 7.81 \%$, respectively; Figures 5a-c and 6). On the other hand, the percentages of superior bulbar conjunctiva cells in $S$ and $G_{2} / M$ phases, $3.06 \pm 0.85 \%$ and $7.24 \pm 3.76 \%$, respectively, were significantly lower than in the other topographical zones $(P<0.01$; Figures $5 \mathbf{a}-\mathbf{c}$ and $\mathbf{6})$. The mean proliferation indexes (MPIs) of the superior tarsal and inferior tarsal-bulbar-fornical conjunctivas, $18.87 \pm 6.13 \%$ and $18.04 \pm 5.36 \%$, respectively, were
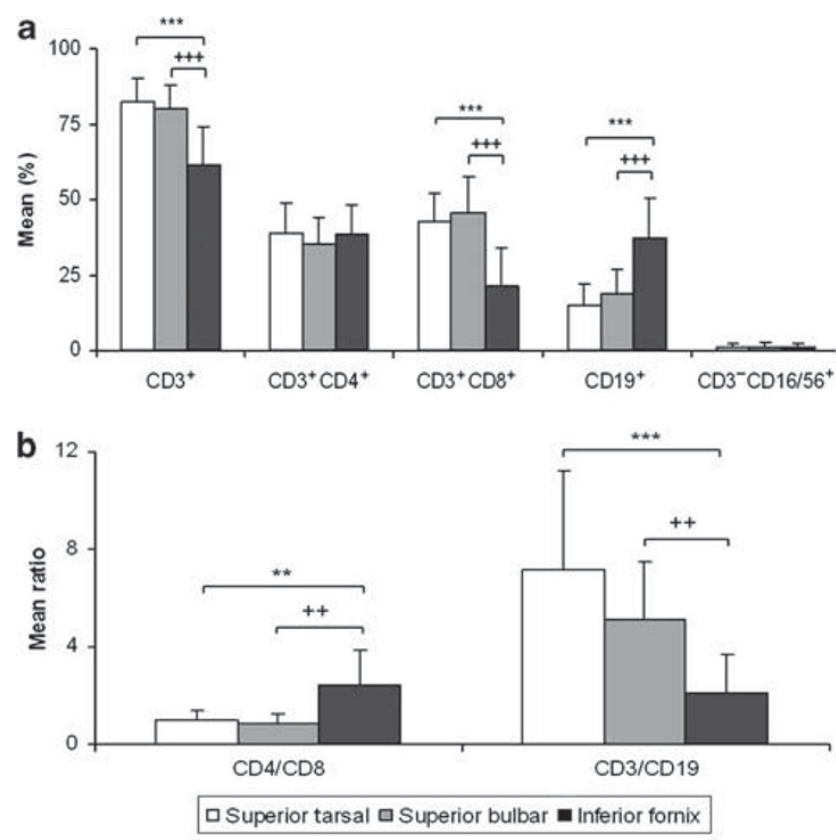

Figure 2 Immunophenotypic analysis of intraepithelial lymphocytes recovered by brush cytology $(\mathrm{BC})$ from superior tarsal and bulbar and inferior tarsal-bulbar-fornical conjunctiva. (a) Mean percent of cells bearing CD3, CD4, CD8, CD19, CD16/56, or combinations thereof. (b) Mean ratios CD4/CD8 and CD3/CD19. ${ }^{++} P<0.01,{ }^{+++} P<0.001$ bulbar vs. fornix; ${ }^{\star \star} P<0.01,{ }^{\star \star \star} P<0.001$ tarsal vs. fornix. 
significantly higher than in the superior bulbar, $11.06 \pm 4.52 \%$ $(P<0.001$; Figure 6). There were no significant differences in the different cell cycle phases or MPI between the superior tarsal and inferior tarsal-bulbar-fornical conjunctival zones (Figure 6).

\section{Correlation analysis}

Correlation between cell cycle phases and cell viability. In the superior tarsal conjunctiva, S-phase cells were positively correlated with the proportion of smaller, less complex cells (Figure 7a) and with the percentage of viable cells (Figure 7b). However, the same cells were negatively correlated both with the proportion of more complex cells (Figure 7c) and with the percentage of early apoptotic cells (Figure 7d) in the less complex cell population.

In the superior bulbar conjunctiva, S-phase cells were positively correlated with the proportion of smaller, less complex cells (Figure 8a) and the viable cells in the less complex population (Figure $\mathbf{8 b}$ ). They were negatively correlated with the proportion of more complex cells (Figure 8c), the less complex cells in early apoptosis (Figure 8d), and dead cells within the more complex (Figure 8e) and less complex (Figure 8f) epithelial cells. The MPI was positively correlated with the viable cells in the less complex population (Figure 8g), but inversely correlated with the less complex cells in early apoptosis (Figure $\mathbf{8 h}$ ).
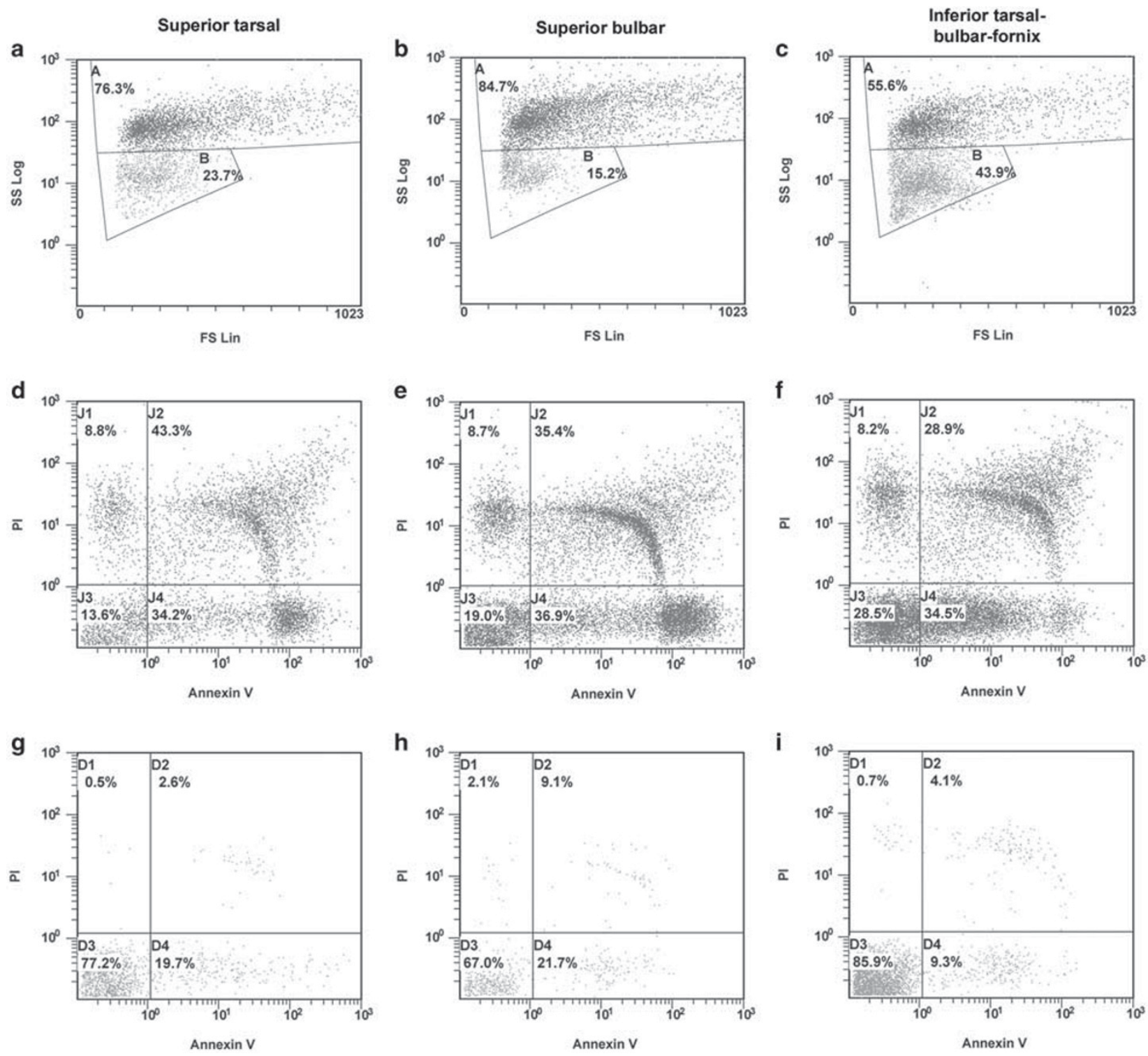

Figure 3 Flow cytometric dot plots of cell viability analysis of conjunctival cells recovered by brush cytology (BC) from representative cases at the three different topographical regions of the normal human conjunctiva. (a-c) Side scatter (SS) vs. forward scatter (FS) dot plot of conjunctival cells showed two different populations: larger, more complex cells (gate A) and smaller, less complex cells (gate B). (d-f) Dot plot of annexin V-FITC vs. PI gated on the larger and more complex cells showed a high level of early (region J4) and late (region J2) apoptotic cells. ( $\mathbf{g}-\mathbf{i})$ Dot plot of annexin V-FITC vs. PI gated on the smaller and less complex cells showed high viability (region D3). FITC, fluorescein isothiocyanate; PI, propidium iodide. The color reproduction of this figure is available on the Mucosal Immunology Journal online (full text HTML version). 
Correlation among IELs, cell cycle, and complexity. In the inferior tarsal-bulbar-fornix conjunctiva, CD $45^{+}$IELs were positively correlated with the proportion of smaller, less complex cells (Figure 9a) and negatively correlated with the proportion of more complex cells (Figure 9b). Similarly, the MPI was positively correlated with $\mathrm{CD} 4{ }^{+} \mathrm{T}$ cells (Figure 9c) and negatively correlated with $\mathrm{CD} 8^{+} \mathrm{T}$ cells (Figure 9d).

\section{In vivo confocal microscopy findings}

In the superior tarsal region, the superficial epithelium consisted of oval cells with dark gray cytoplasm, granular and light gray cell borders, and no visible nucleus (Figure 10a). Basal epithelial cells appeared smaller than those in the superficial
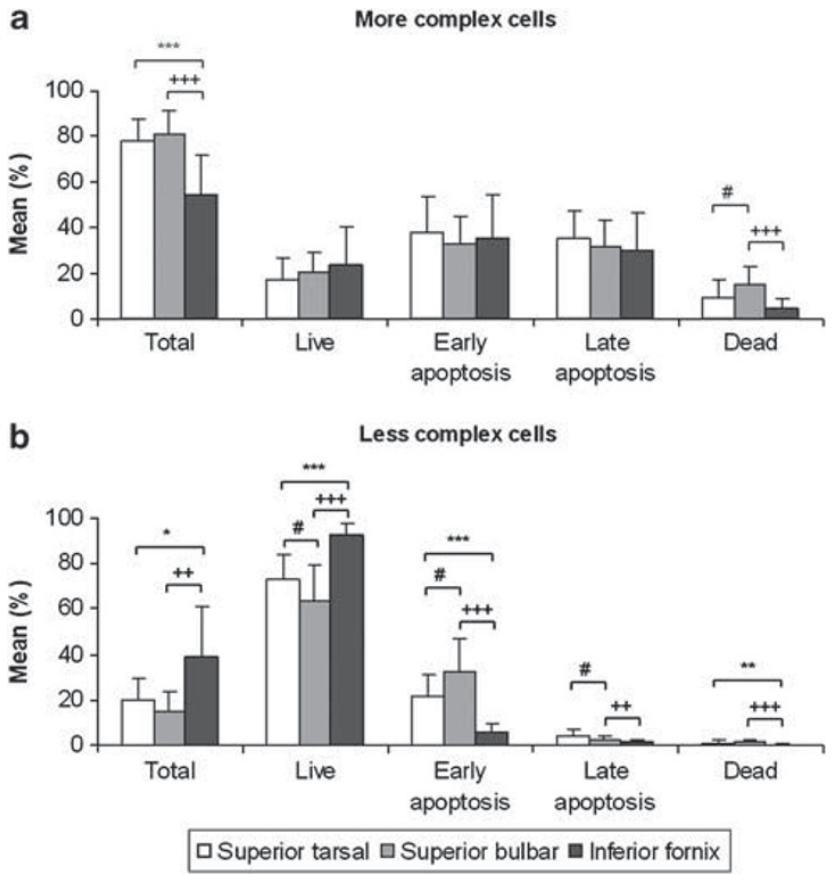

Figure 4 Cell viability analysis in conjunctival cells obtained by brush cytology (BC) from superior tarsal and bulbar and inferior tarsal-bulbarfornical conjunctiva. Mean percent of total, live, early and late apoptotic, and dead cells in the (a) larger, more complex population and the

(b) smaller, less complex population. ${ }^{++} P<0.01,{ }^{+++} P<0.001$ bulbar vs. fornix; ${ }^{\star} P<0.05$; ${ }^{\star \star} P<0.01,{ }^{\star \star \star} P<0.001$ tarsal vs. fornix, ${ }^{\#} P<0.05$ tarsal vs. bulbar. epithelium (Figure 10b). Similar images showing the grooves left by the nylon bristles of the brush were obtained at a depth of $8 \mu \mathrm{m}$ (Figure 10c) and $24 \mu \mathrm{m}$ (Figure 10d). There were no BC grooves at $34 \mu \mathrm{m}$ depth (Figure 10e); however, epithelial cells were still present.

In the superficial layers of the superior bulbar conjunctiva, small hyporeflective epithelial cells with pyknotic nuclei were present throughout the field both before (Figure 11a) and after (Figure 11b) BC. Large, hyper-reflective cells, presumably goblet cells (arrows), were also visible. Before (Figure 11c) and after (Figure 11d) BC, basal epithelial cells were defined by hyper-reflective cell borders and indiscernible nuclei.

\section{DISCUSSION}

Previously, the presence of CALT was considered as a sign of clinical inflammation and not recognized as part of the mucosal immune system. ${ }^{17-19}$ However, further evidence has shown that CALT is a normal, non-inflammatory component of the human ocular surface and contributes in the secretion of immune mediators as well as in the regulation of the local immune response. ${ }^{20-27} \mathrm{~A}$ better understanding of this non-pathological tissue will help to further the study of the ocular surface in inflammatory disorders.

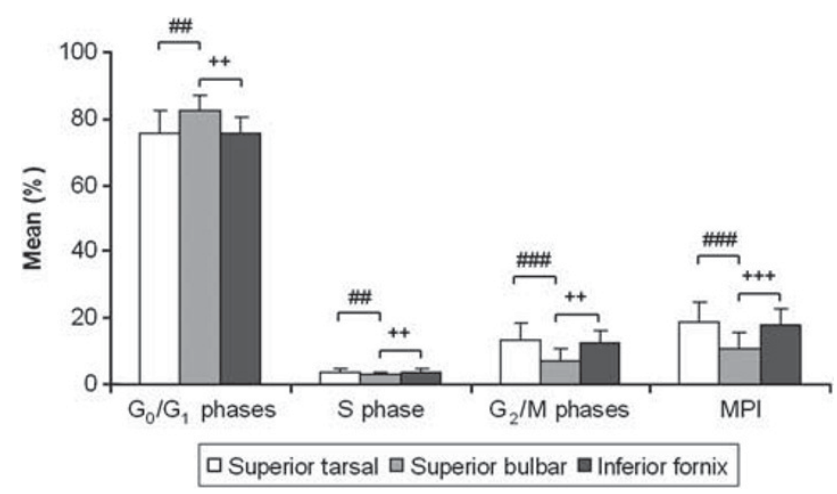

Figure 6 Cell cycle analysis in conjunctival cells obtained by brush cytology (BC) from superior tarsal and bulbar and inferior fornical conjunctiva. ${ }^{++} P<0.01,{ }^{+++} P<0.001$ bulbar vs. fornix, ${ }^{\# \#} P<0.01$,

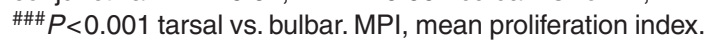
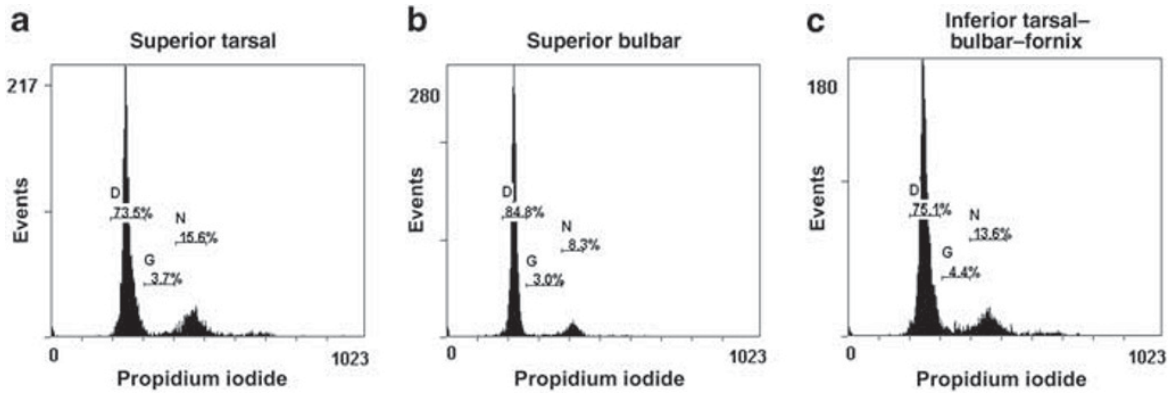

Figure 5 Flow cytometric dot plots of cell cycle analysis of conjunctival cells recovered by brush cytology (BC) from representative cases at the three different topographical regions of the normal human conjunctiva. (a-c) Linear fluorescence histogram of propidium iodide (PI) showed different phases of cell cycle (D, $2 n$ cells in $G_{0}$ and $G_{1}$ phases; $G$, cell population in the $S$ phase; $N, 4 n$ cells in $G_{2}$ and $M$ phases). 
In normal conditions, a delicate balance is reached between the IEL-mediated production of inflammatory mediators and the active generation of immune tolerance. However, in ocular surface diseases such as dry eye syndrome, allergic conjunctivitis, etc., inflammation and subsequent increased epithelial cell apoptosis are thought to be mediated by an increase in CD4 ${ }^{+}$IELs. ${ }^{28-33}$ Thus, it is essential to know the resident lymphocyte population and their subtypes in the healthy human conjunctiva.

As we reported previously, ${ }^{29,34}$ there was a small population of $\mathrm{CD} 45^{+}$cells in the conjunctival epithelium of all subjects who participated in the study. The highest levels of CD45 infiltration were in the superior tarsal conjunctiva, followed closely by the inferior tarsal-bulbar-fornix and the upper bulbar conjunctiva, where only few lymphoid cells were detectable (Figure 12a). Similar to our own findings, Knop and Knop, ${ }^{9}$ using human tissue whole mounts from healthy conjunctivas, reported tarsal predominance of subepithelial diffuse lymphoid tissue, mostly T lymphocytes and plasma cells, and lymphoid follicles. This is probably due to the accumulation of foreign matter and hence the amount of antigens in this region of the conjunctiva. In contrast, earlier studies reported the highest density of diffuse lymphoid tissue in either the bulbar or fornical conjunctivas. ${ }^{5,6,8}$ However, further and more extended analysis of conjunctival tissue demonstrated the preponderance of lymphoid tissue in the tarsal zones. ${ }^{9}$ The high levels of IELs that we found in the inferior fornix can probably be explained by the limitations of the Cytobrush-Plus GT, which because of its shape, collects cells from a wider region than just the fornix. Therefore, our fornical samples also contained tarsal and bulbar cells that may have contributed to the increased IEL levels.

Our immunophenotypic analysis by flow cytometry demonstrated that the majority of the IELs that reside in the epithelial compartment of the healthy conjunctiva are T lymphocytes. Similar results have been reported by others using histological methods. ${ }^{5-8}$ In the superior conjunctival regions, the ratio of CD3/CD19 was approximately of 6:1, suggesting a strong predominance of $\mathrm{T}$ over $\mathrm{B}$ cells. However, in the inferior tarsal-bulbar-fornix, the ratio decreased to 2:1, indicating a high percentage of $B$ lymphocytes. These findings suggest that in the inferior tarsal-fornix region, where the conjunctival epithelium
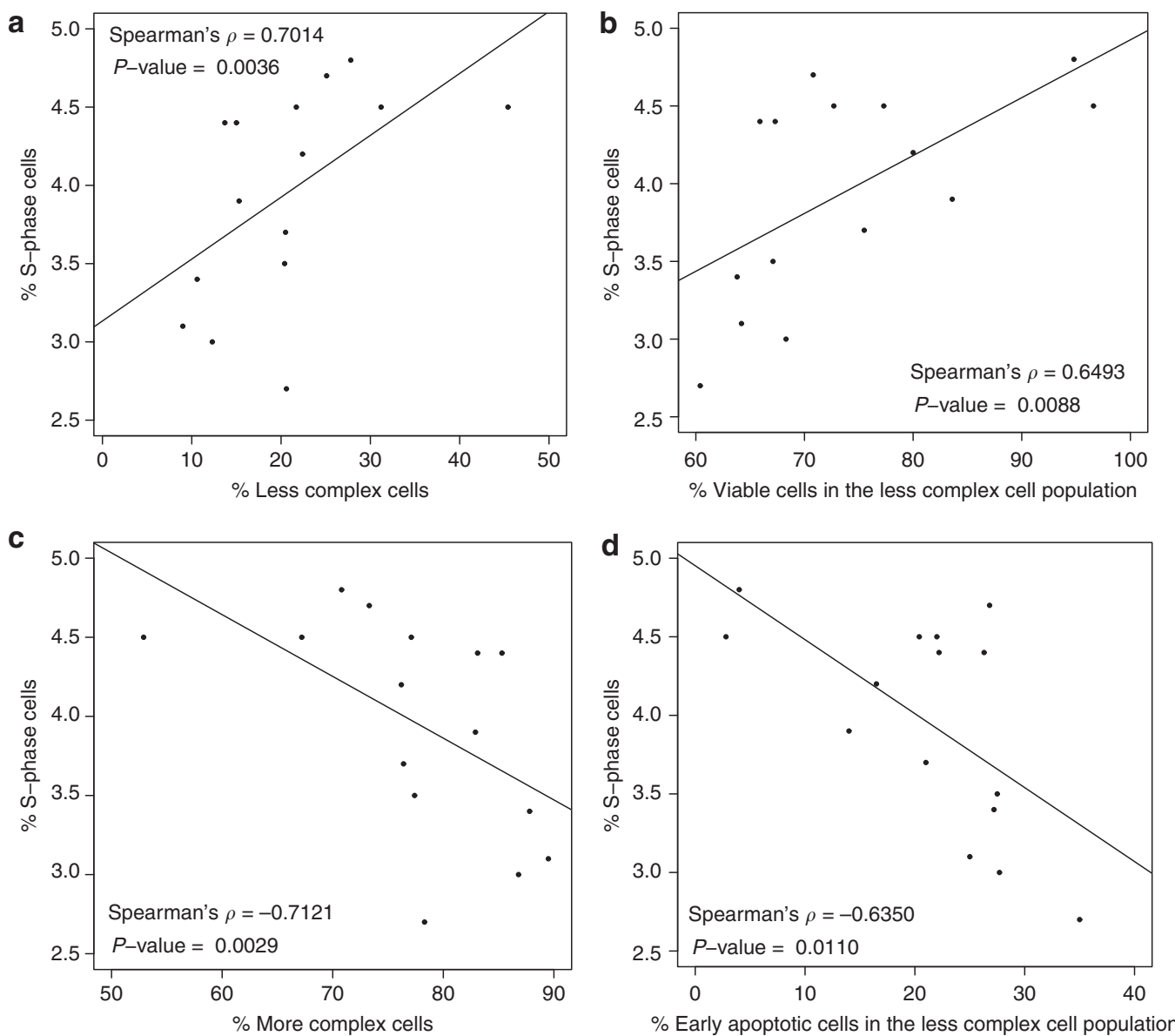

Figure 7 Correlation between cell cycle, viability, and cell complexity in the superior tarsal conjunctiva. (a) S-phase cells were positively correlated with the proportion of less complex cells and (b) with the percentage of viable cells and negatively correlated with the (c) proportion of more complex cells and with the (d) the percentage of early apoptotic cells in the less complex cell population. The Spearman's $\rho$ correlation coefficients are shown in each graph. 

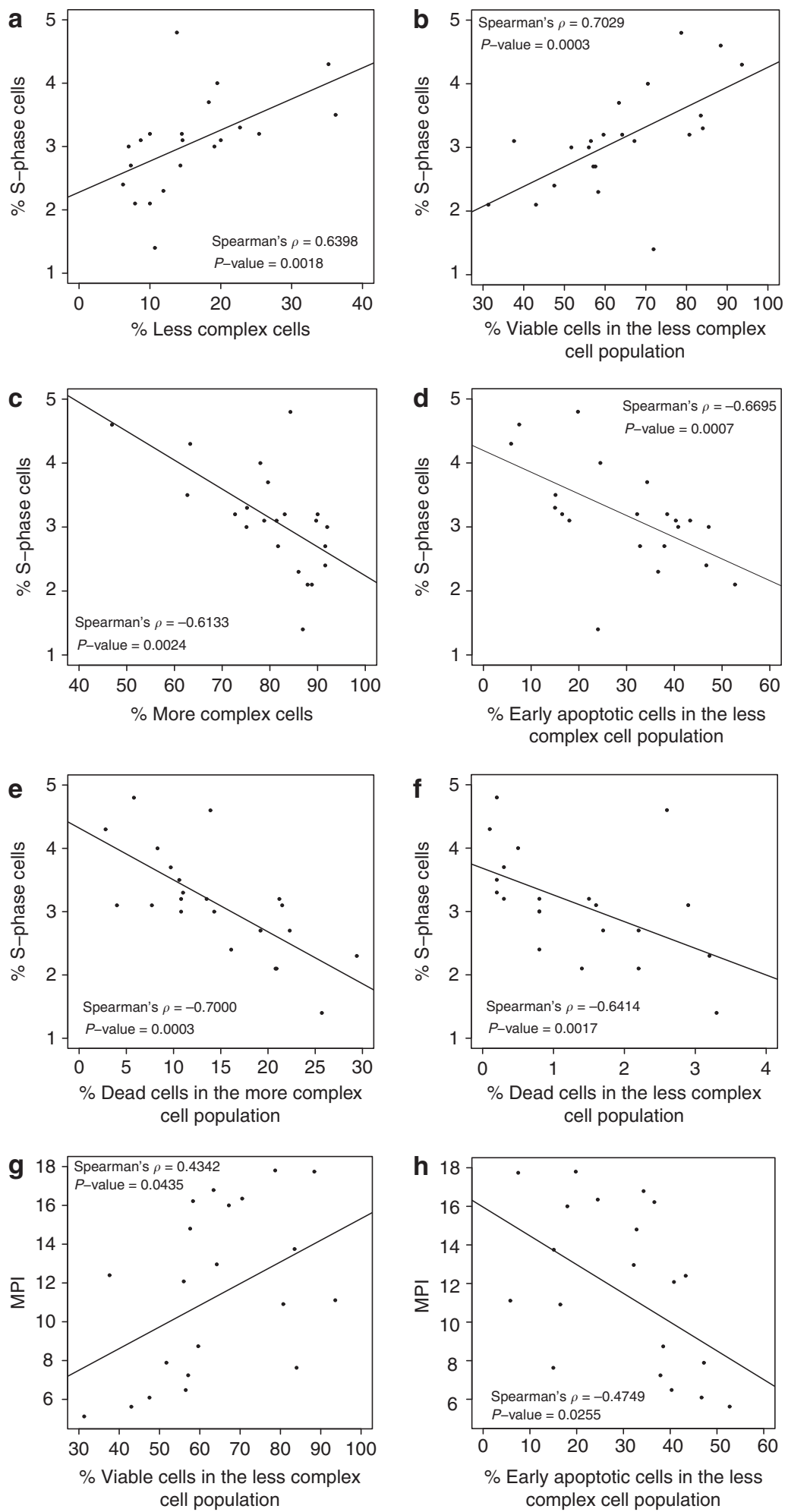

Figure 8 Correlation between cell cycle, viability, and cell complexity in the superior bulbar conjunctiva. (a) S-phase cells were positively correlated with the proportion of less complex cells and (b) with the percent of viable cells in the less complex cell population and negatively correlated with (c) the proportion of more complex cells, (d) less complex cells in early apoptosis, and dead cells within the (e) more and (f) less complex epithelial cells. (g) The mean proliferation index (MPI) was positively correlated with the viable cells in the less complex population and (h) negatively correlated with the less complex cells in early apoptosis. The Spearman's $\rho$ correlation coefficients are shown in each graph. 

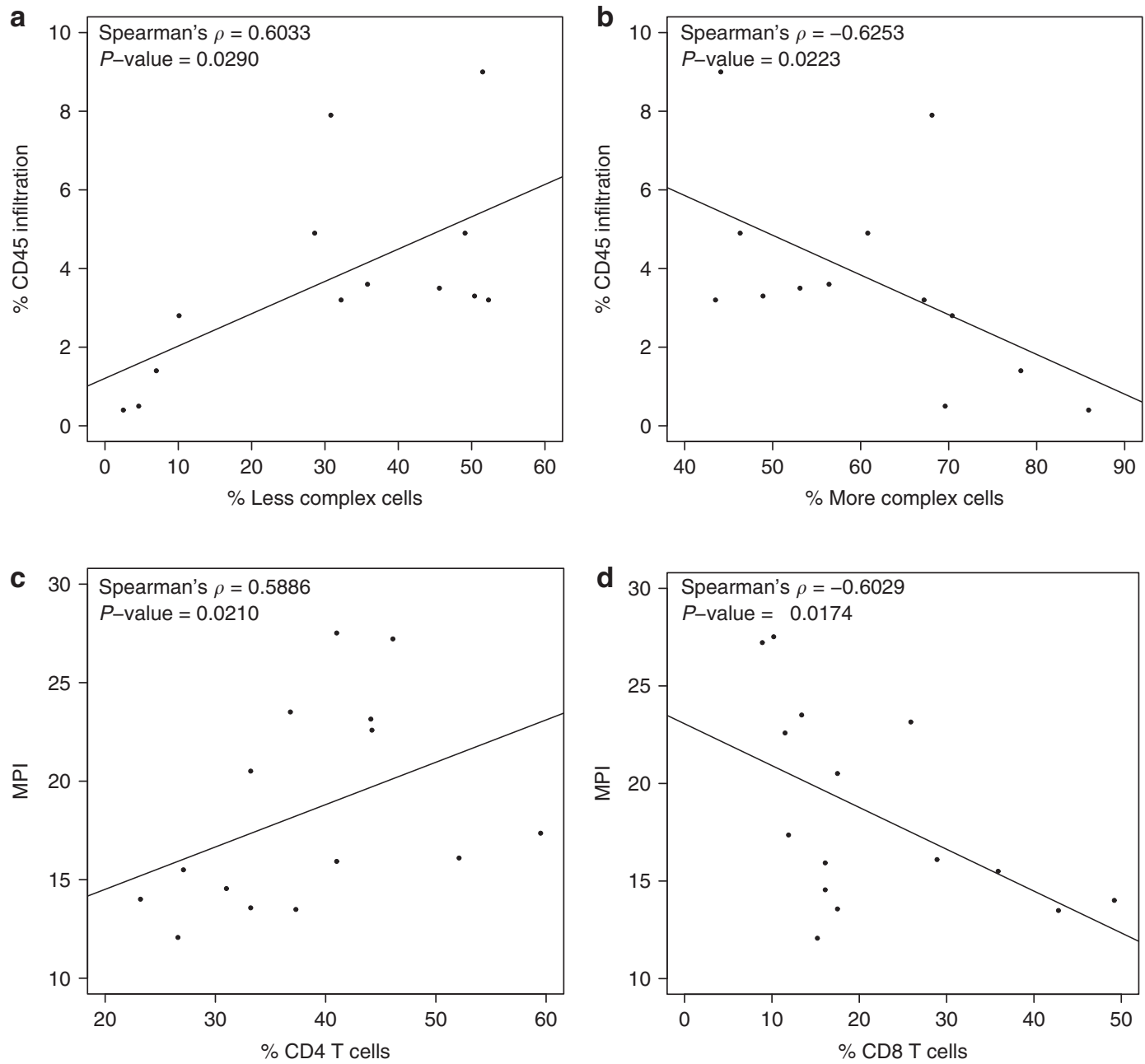

Figure 9 Correlation between intraepithelial lymphocytes (IELs), cell cycle, viability, and cell complexity in the inferior tarsal-bulbar-fornix conjunctiva. (a) CD45+ IELs were positively correlated with the proportion of less complex cells and (b) negatively correlated with the proportion of more complex cells. (c) The mean proliferation index (MPI) was positively correlated with $\mathrm{CD}^{+}{ }^{+} \mathrm{T}$ cells and (d) negatively correlated with $\mathrm{CD} 8^{+} \mathrm{T}$ cells. The Spearman's $\rho$ correlation coefficients are shown in each graph.

is composed of fewer epithelial cell layers, ${ }^{35,36}$ it is possible that the BC technique may occasionally obtain lymphocytes from organized lymphoid follicles. This fact is in total concordance with the previous report by Knop and Knop ${ }^{22}$ with regard to the composition of both diffuse and organized CALT. The predominance of $\mathrm{CD} 8^{+}$over $\mathrm{CD} 4^{+} \mathrm{T}$ cells in the conjunctival epithelium of healthy donors has also been described widely. ${ }^{5-8,37}$ Our results are consistent with these reports, except in the fornical zone where there were more $\mathrm{CD} 4^{+}$than $\mathrm{CD} 8^{+} \mathrm{T}$ cells. This may be due to the presence of scattered $\mathrm{CD} 4^{+} \mathrm{T}$ cells that normally are associated with follicular B lymphocytes. ${ }^{5,6,8,22}$ Moreover, this may reflect a topographical differential immune function of this conjunctival area where most of the antigens from the eye surface finally accumulate because of normal blinking and tearing processes.

Apoptosis is a physiological process of cell death that occurs in most tissues, including the conjunctiva. This process plays a key role in the maintenance of cellular homeostasis and regulation of the immune response. Our study was based on the finding that apoptotic cells are distributed throughout the whole structure of the normal conjunctiva. ${ }^{15}$ As we reported previously, ${ }^{29,34}$ two different cell populations were present in all BC samples. The predominant population consisted of cells that were larger and more complex because of higher cytoplasmic granularity. They were also less viable. These cells are probably located in the more superficial conjunctival layers. The less abundant population consisted of smaller, less complex, and more viable cells that are preferentially situated in the more basal layers of the epithelium. These results are consistent with previous studies, which reported that human conjunctival epithelium constitutively expresses pro-apoptotic proteins such as Bax, Bad, Fas (CD95), and CD40, predominantly in surface epithelial cells, and apoptosis-inhibitory factors such as the Bcl-2 protein, mainly present in basal layers of the conjunctiva. ${ }^{13-15}$ Correlation analysis confirmed that this population of less complex cells is likely to consist of a mixture of basal epithelial cells and IELs. 


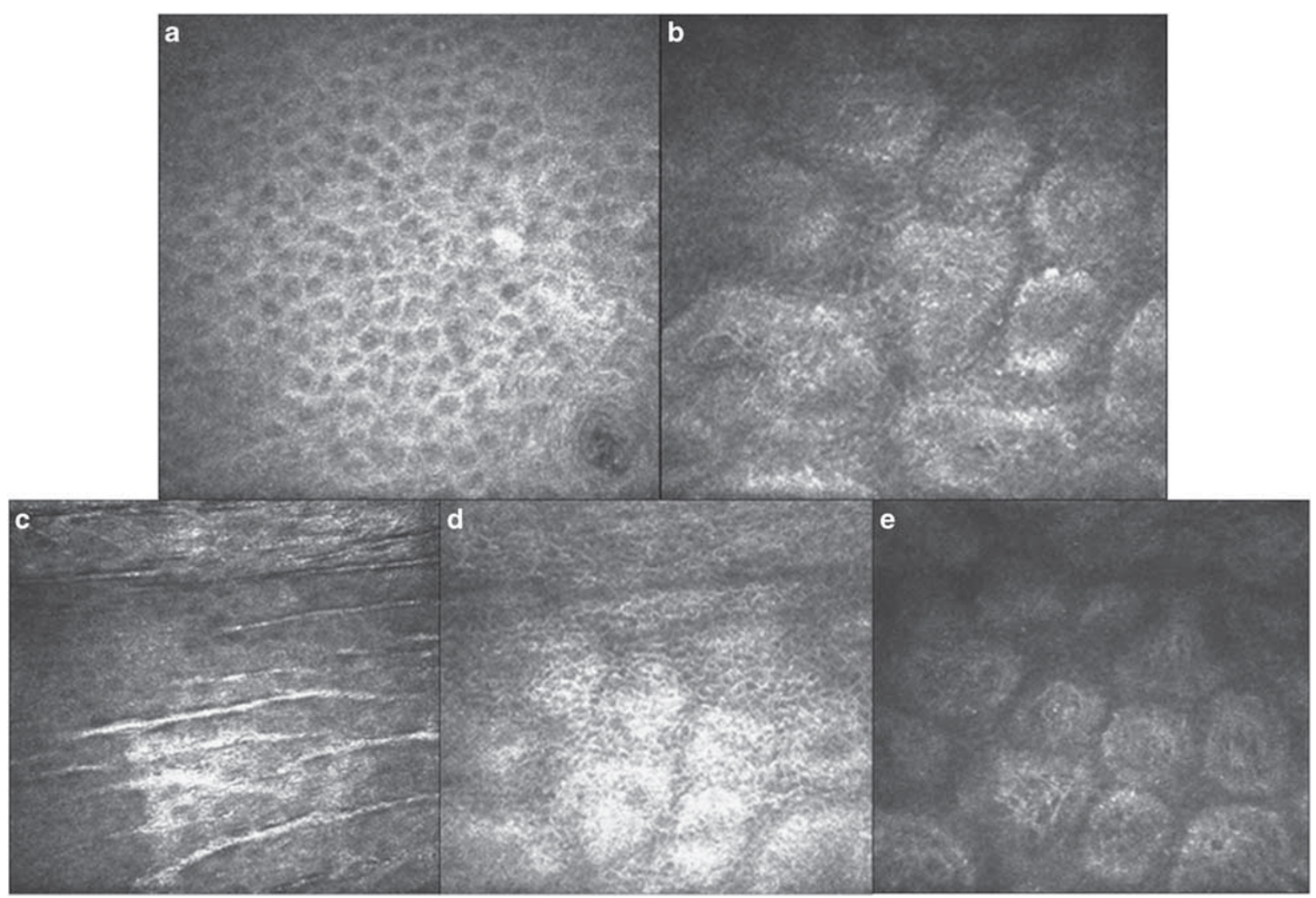

Figure 10 In vivo confocal microscopy of normal tarsal conjunctiva. (a) Superficial epithelium and (b) basal epithelial cells before brush cytology (BC). (c) Superficial epithelium and (d, e) basal epithelial cells after BC, 24 and $34 \mu \mathrm{m}$ depth, respectively. The highly reflective regions observed in the background of panels $\mathbf{b}, \mathbf{d}$ and $\mathbf{e}$ are back reflections from the anterior aspects of Meibomian gland acini. All images, $400 \times 400 \mu \mathrm{m}^{2}$.

The more complex cells probably consist mainly of superficial epithelial and goblet cells, as previous reports using confocal microscopy have suggested. ${ }^{38}$

Here we describe for the first time, to our knowledge, the distribution pattern of live, apoptotic (early and late), and dead cells in different anatomical zones of the healthy conjunctiva (Figure 12b, c). We found significant differences mainly between the superior conjunctival regions and the inferior fornical region; however, the mixed collection of conjunctival cells from the inferior tarsal-bulbar-fornix did not allow us to draw firm conclusions about that region. Our results also showed increased apoptosis levels in the more complex cells of the superior tarsal conjunctiva compared with the superior bulbar conjunctiva. This may be due to increased friction between tarsal conjunctiva and the cornea during blinking. The tarsal region is the only area where muscular force plays a part in the application of the conjunctiva to the underlying structures. For that reason there will be greater friction between the tarsal conjunctival and corneal surfaces. ${ }^{39}$ In contrast, cells of the upper bulbar conjunctiva showed lower viability and higher apoptosis levels in the less complex cells than the superior tarsal conjunctiva. Collectively, these results suggest a differential distribution of apoptotic cells in the normal conjunctiva, not only between basal and superficial cells as others reported previously, ${ }^{15}$ but also between different topographical zones.

Cell proliferation of the conjunctival epithelium has received little attention compared with corneal epithelium. In this study, we measured by flow cytometry the DNA content of BC-recovered conjunctival cells to get an accurate indication of cell cycle stage, which may serve as a marker of proliferative state. We found that the majority of conjunctival cells collected from healthy donors was in the $G_{0} / G_{1}$ phase, followed by $G_{2} / M$ phase, and lastly by the $S$ phase (Figure 12d). The small population of cells in the process of synthesizing DNA was positively correlated with the proportion of viable and less complex cells. This suggests that in the basal layers of the normal conjunctival epithelium there is a high proliferation of IELs, probably due to the presence of antigens migrating from more superficial layers.

Our results also revealed significant differences between the three conjunctival zones regarding the phases of the cell cycle (Figure 12d). The superior bulbar region had the highest levels of cells in $G_{0} / G_{1}$ phases and the lowest MPI, suggesting that this zone might be the predominant site of conjunctival epithelial slow-cycling stem cells, as others authors have suggested previously. ${ }^{16,40}$ However, this contrasts with other data suggesting that conjunctival stem cells might be 


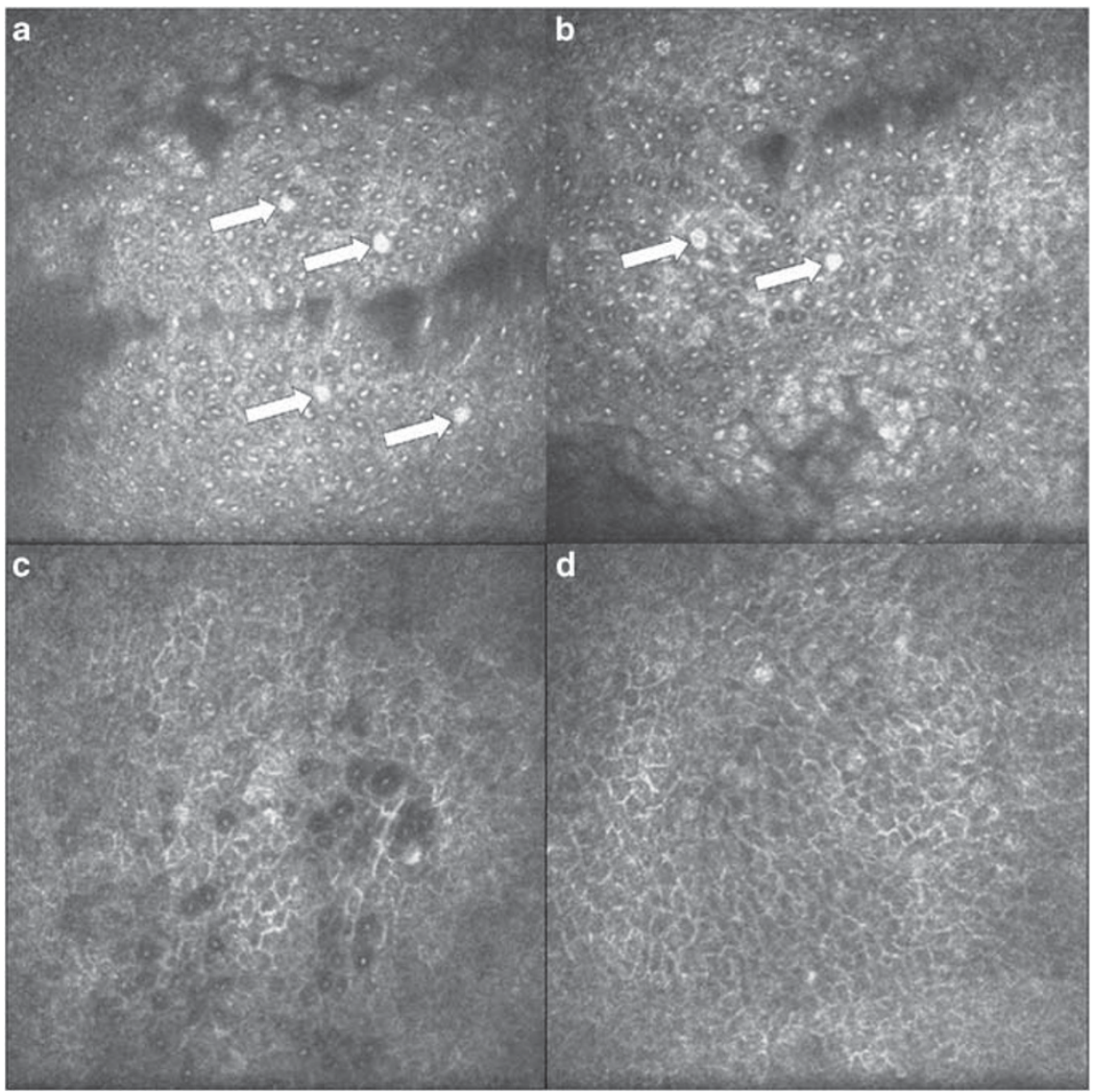

Figure 11 In vivo confocal microscopy of normal superior bulbar conjunctiva. Superficial epithelium (a) before and (b) after brush cytology (BC) with goblet cells (arrows) among epithelial cells. Basal epithelial cells (c) before and (d) after BC. All images, $400 \times 400 \mu \mathrm{m}^{2}$.

concentrated in the fornix. ${ }^{16,41-44}$ The high MPI that we found in the fornical conjunctiva can probably be explained, as we mentioned above, by the mixed collection of conjunctival cells from the inferior tarsal-bulbar-fornix. The mucocutaneous junction of the rabbit eyelid ${ }^{45,46}$ and the rat palpebral conjunctiva ${ }^{47}$ have also been postulated as sources of replacement for the conjunctival epithelial cells, suggesting that the location of dividing cell populations might vary between species. In addition, stem cells with high in vitro proliferative potential are usually located in the thicker epithelial zones. ${ }^{48,49}$ This is especially true for the bulbar epithelium, which is composed up to eight layers, in contrast to the tarsal epithelium where only of 2 to 3 cell layers have been observed. ${ }^{35}$

In summary, our results allow us to speculate that each topographical zone within the conjunctiva could play a specific differential role in the regulation of immune responses. Specifically, the inferior tarsal-bulbar-fornical region, because of its high numbers of follicular B lymphocytes and CD4 ${ }^{+}$ $\mathrm{T}$ cells, would act as an immune inductive site where antigen processing, lymphocyte activation and antibody production could occur (organized CALT). In contrast, the upper tarsal and bulbar conjunctivas would represent the effector sites (diffuse CALT) where terminally differentiated T cells, mainly diffusely scattered CD ${ }^{+} \mathrm{T}$ cells, could perform effector functions needed for host defense such as the releasing antimicrobial defensins, killing virus-infected cells and secreting inflammatory cytokines that inhibit replication of the pathogen. The low MPI found in the superior bulbar region also allow us to hypothesize that this zone might act as a niche for conjunctival epithelial stem cells.

Moreover, our results could be very helpful for comparisons of the conjunctival immunological function between ocular surface disease patients and healthy subjects. Indeed, in a previous study with evaporative-type dry eye patients, ${ }^{29}$ apoptosis, IEL phenotypes, and MPI were altered in the patients either at diagnosis or after 2 months of corticosteroids therapy. This suggests a potential role for these parameters as diagnostic and/or disease progression biomarkers that warrants further investigation.

\section{METHODS}

Subjects. This study was approved by the institutional review board of the University of Valladolid and followed the tenets of the Declaration of Helsinki. In all, 63 healthy donors ( 33 females and 30 males, mean \pm s.d., age $75 \pm 11$ years) agreed to participate in this study after the procedures were fully explained and informed consents were signed. BC samples were obtained from the superior tarsal $(n=16 ; 8$ females and 8 males, age $77 \pm 13$ years) and bulbar ( $n=30 ; 16$ females and 14 males, age $74 \pm 10$ 

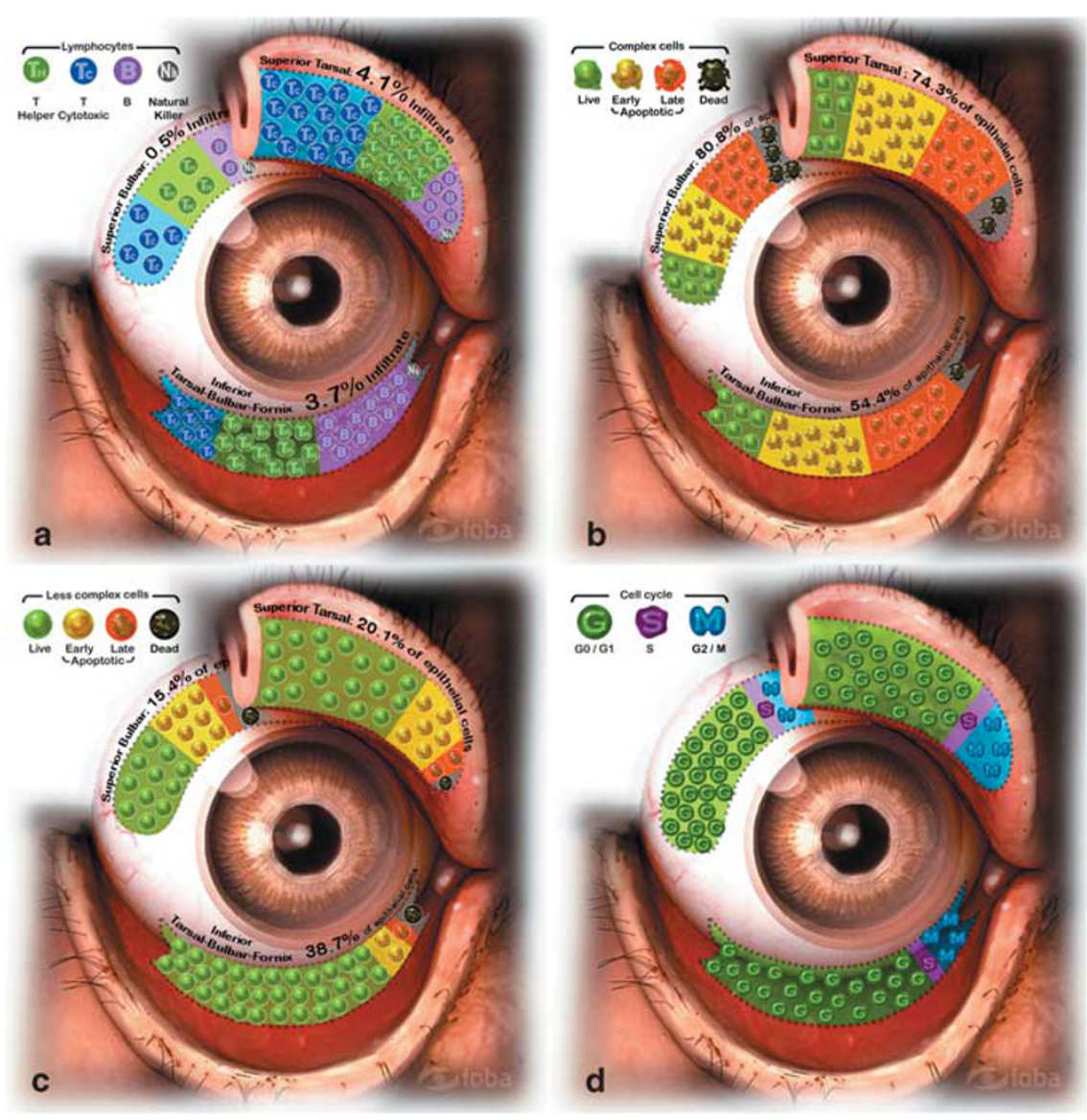

Figure 12 Topographical proportions of intraepithelial lymphocytes (IELs), live and dead cells, early and late apoptotic cells, and cell cycle phases in the three sampled regions of the normal human conjunctiva. (a) Proportions of Th, Tc, B, and NK cells. (b) Proportions of live, dead, early apoptotic, and late apoptotic complex cells. (c) Proportions of live, dead, early apoptotic, and late apoptotic less complex cells. (d) Proportions of cells in $G_{0} / G_{1}, S$, and $G_{2} / M$ phases of the cell cycle. The number of symbols represents the density of a given phenotype, whereas the underlying colored areas represent the cell percentages in each technique. Dotted lines in each figure represent the brush cytology (BC) sampling area within the three regions. Moreover, the percentages of (a) CD45 ${ }^{+}$IELs and the percentage of (b) more and (c) less complex cells in the different topographical areas are also shown.

years); and inferior tarsal-bulbar-fornical conjunctiva ( $n=17 ; 9$ females and 8 males, age $75 \pm 11$ years) before cataract surgery in patients who were otherwise healthy and had no systemic or previous ocular disease other than cataract. None of the subjects was atopic or had any allergies, wore contact lenses, or was being treated with systemic steroids, immunosuppressants, or topical medications at the time of the study.

Conjunctival brushing. We chose $\mathrm{BC}$ as the sampling technique based on previous reports. ${ }^{50,51}$ Conjunctival cells were always collected by the same clinician (co-author RMS) as described previously. ${ }^{29,34}$ Only one eye of each subject was sampled to avoid any bias related to immune inter-eye dependency. ${ }^{28}$ Briefly, eyes were anesthetized with topical $0.4 \%$ oxybuprocaine drops for $10 \mathrm{~min}$, and then one rotation of the CytobrushPlus GT (Medscand Medical AB, Molmö, Sweden) was performed on the superior tarsal, superior bulbar, or inferior tarsal-bulbarfornical conjunctiva. Only one location was sampled in each subject. Cells were then detached from the brush by gentle rotation for $30 \mathrm{~s}$ in an Eppendorf tube containing $1.2 \mathrm{ml}$ of a 1:1 mixture of Dulbecco's modified Eagle's medium and Ham F12 medium supplemented with 10\% fetal bovine serum (Gibco-Invitrogen, Inchinnan, UK). BC was then performed three more times at the same location, and the samples were detached subsequently in the same tube before being transported to the laboratory for flow cytometry analysis, which was done $<30$ min after sampling.

Flow cytometry analysis. Immunophenotype, viability, and proliferative capacity of the BC-recovered cells were analyzed by flow cytometry. First, each cell suspension was divided equally into four different tubes of $300 \mu \mathrm{l}$. Each tube was then washed with $2 \mathrm{ml}$ of Cell Wash Solution (BD Biosciences, San Jose, CA), centrifuged at $500 \times \mathrm{g}$ for $5 \mathrm{~min}$, and analyzed by a panel of specific immune cell markers. After removal of the supernatant, the remaining cells were processed for three different analyses: cell linage (Tubes 1 and 2), viability (Tube 3), and cell cycle (Tube 4). For each assay, at least 5,000 conjunctival cells were analyzed. The flow cytometry analysis was performed with a Cytomics FC 500 Cytometer (Beckman-Coulter, Fullerton, CA) using $488 \mathrm{~nm}$ excitation with an argon-ion laser for fluorescein isothiocyanate (FITC), phycoerythrin (RD1), phycoerythrin-Texas Red-X (ECD), propidium iodide, phycoerythrin-cyanine 5 , and phycoerythrin-cyanine 7 . The data collected were analyzed using the Cytomics RXP software program (Beckman-Coulter). Controls included crossreactivity of the fluorescence signals of each channel, as well as isotype-matched unspecific monoclonal antibodies used as negative controls. Flow cytometry gates were applied as appropriate to analyze the cell phenotype, apoptotic stage, and cell cycle. 
Cell lineage analysis. The phenotype of the BC-recovered conjunctival cells was determined by staining with two panels of fluorochromeconjugated mouse anti-human monoclonal antibodies as described previously. ${ }^{29}$ In the first panel, we used the following monoclonal antibodies: anti-CD3 phycoerythrin-cyanine 5 (clone UCHT1), antiCD4 RD1 (clone SFCI12T4D11), anti-CD8 ECD (clone SFCI21Thy2D), and anti-CD45 FITC (clone B3821F4A). All antibodies used in this panel were obtained from Beckman-Coulter. We used the following monoclonal antibodies in the second panel: anti-CD3 FITC (clone 33-2A3) from Immunostep (Salamanca, Spain), anti-CD16 phycoerythrin (clone B73.1), and anti-CD56 phycoerythrin (clone NCAM 16.2) from Caltag Laboratories (Burlingame, CA), and anti-CD19 phycoerythrin-cyanine 5 (clone J4.119) and anti-CD45 phycoerythrin-cyanine 7 (clone J33) from Beckman-Coulter. Cell suspensions were incubated in the dark with these antibodies at room temperature for $15 \mathrm{~min}$. They were then incubated in the dark with $1 \mathrm{ml}$ of FACS Lysing solution (BD Biosciences) at room temperature for $15 \mathrm{~min}$ to fix the cells. Afterwards, the cells were gently agitated, and flow cytometry analysis performed.

Cell viability analysis. The percentages of live, early and late apoptotic, and dead BC-recovered conjunctival cells were determined using an annexin V-FITC and propidium iodide commercial kit (Beckman-Coulter) as described previously. ${ }^{29,34}$

Cell cycle analysis. The DNA content of the BC-recovered conjunctival cells was determined by staining with propidium iodide after cell permeabilization (Coulter DNA Prep Reagents Kit; Beckman-Coulter) as described previously. ${ }^{29,34} \mathrm{~A} \mathrm{G}_{0 / 1}$ doublet discrimination using pulse height vs. area ${ }^{52}$ was performed before cell cycle phase analysis. The MPI was calculated as the ratio of $\left(S+G_{2} / M\right) /\left(S+G_{2} / M+G_{0} / G_{1}\right)$, where $S$ was the percentage of cells in the $S$ phase, $G_{2} / M$ the percentage of $4 n$ cells in $G_{2}$ and $M$ phases, and $G_{0} / G_{1}$ the percentage of $2 n$ cells in $G_{0}$ and $\mathrm{G}_{1}$ phases.

In vivo confocal microscopy. The superior tarsal and bulbar conjunctivas of two healthy volunteers who participated in this study were examined by in vivo laser scanning confocal microscopy with a Heidelberg Retinal Tomograph (HRT III; Heidelberg Engineering GmbH, Heidelberg, Germany) with a Rostock corneal module (Heidelberg Engineering $\mathrm{GmbH})$. This instrument incorporated a $\times 60$ objective water-immersion lens with a numerical aperture of 0.9 (Zeiss, Oberkochen, Germany). The optical configuration of this instrument resulted in an image dimension of $400 \times 400 \mu \mathrm{m}^{2}$, with a transverse resolution of $2 \mu \mathrm{m}$ and an optical section thickness of about $4 \mu \mathrm{m}$.

The conjunctiva of each subject was examined immediately before and after BC. To avoid cross-contamination and optimize optical quality, a new disposable TomoCap (Heidelberg Engineering $\mathrm{GmbH}$ ) was used for each participant. To ensure optical coupling of the objective lens of the Rostock corneal module with the back surface of the TomoCap, the TomoCap was filled with Viscotears (Carbomer 980, $0.2 \%$; Novartis Farmaceutica SA, Barcelona, Spain) before fitting it to the Rostock corneal module. The eye was anesthetized with $0.1 \%$ tetracaine hydrochloride plus $0.4 \%$ oxybuprocaine hydrochloride (Alcon Cusí SA, El Masnou-Barcelona, Spain) and another drop of Viscotears was instilled into the eye to aid subject comfort. To capture images of the palpebral conjunctiva, each subject was instructed to direct his/her gaze downward while the upper lid was everted. The surface of the TomoCap was positioned in the center of the everted palpebral conjunctiva. Images of the bulbar conjunctiva were captured at four cardinal locations, superior, inferior, nasal, and temporal, relative to the cornea. To achieve this, the subject was instructed to direct his/her gaze extremely towards the opposite direction of the region being imaged. The surface of the TomoCap was positioned on the conjunctiva such that the center of the applanating surface was about $2-4 \mathrm{~mm}$ from the limbus. For each location on the conjunctiva, at least 50 digital images were captured from the superficial and deep layers and the underlying stroma. All images were scrutinized and representative images of good quality were selected for qualitative evaluation and presentation.

Statistical analysis. Statistical analysis was carried out by a licensed statistician (co-author MEM) using the Statistical Package for the Social Sciences software package (SPSS 15.0 for Windows, Chicago, IL). The percentages of events obtained by flow cytometry analysis were expressed as means \pm s.d.s. The non-parametric Kruskal-Wallis test was used to analyze multiple comparisons between the different conjunctival regions. When the data were normally distributed, one-way analysis of variance was used. Correlations between flow cytometry data were determined by the Spearman's rho correlation coefficient. $P<0.05$ was the criterion of significance for all statistical tests.

\section{ACKNOWLEDGMENTS}

This study was supported by research grants from Junta de Castilla y León, Spain (VA056A08) and Regenerative Medicine and Cell Therapy Networking Center of Castilla y León, Spain. We thank Beatriz E. Ramírez, $\mathrm{MD}$, and Darío M. Victoria, MD, for their assistance with the confocal microscopy examination.

\section{DISCLOSURE}

The authors declared no conflict of interest.

(C) 2012 Society for Mucosal Immunology

\section{REFERENCES}

1. Paulsen, F. Functional anatomy and immunological interactions of ocular surface and adnexa. Dev. Ophthalmol. 41, 21-35 (2008)

2. McDermott, A.M. The role of antimicrobial peptides at the ocular surface. Ophthalmic Res. 41, 60-75 (2009).

3. Garreis, F., Gottschalt, M. \& Paulsen, F.P. Antimicrobial peptides as a major part of the innate immune defense at the ocular surface. Dev. Ophthalmol. 45, 16-22 (2010)

4. Mohammed, l. et al. Localization and gene expression of human betadefensin 9 at the human ocular surface epithelium. Invest. Ophthalmol. Vis. Sci. 51, 4677-82 (2010)

5. Sacks, E.H., Wieczorek, R., Jakobiec, F.A. \& Knowles, D.M. Lymphocytic subpopulations in the normal human conjunctiva. A monoclonal antibody study. Ophthalmology 93, 1276-83 (1986).

6. Dua, H.S. et al. Mucosa specific lymphocytes in the human conjunctiva, corneoscleral limbus and lacrimal gland. Curr. Eye Res. 13, 87-93 (1994).

7. Wotherspoon, A.C., Hardman-Lea, S. \& Isaacson, P.G. Mucosaassociated lymphoid tissue (MALT) in the human conjunctiva. J. Pathol. 174, 33-37 (1994).

8. Hingorani, M., Metz, D. \& Lightman, S.L. Characterisation of the normal conjunctival leukocyte population. Exp. Eye Res. 64, 905-12 (1997).

9. Knop, N. \& Knop, E. Conjunctiva-associated lymphoid tissue in the human eye. Invest. Ophthalmol. Vis. Sci. 41, 1270-9 (2000).

10. Brignole, F., De Saint-Jean, M., Goldschild, M., Becquet, F., Goguel, A. \& Baudouin, C. Expression of Fas-Fas ligand antigens and apoptotic marker APO2.7 by the human conjunctival epithelium. Positive correlation with class II HLA DR expression in inflammatory ocular surface disorders. Exp. Eye Res. 67, 687-97 (1998).

11. Brignole, F., Pisella, P.J., Goldschild, M., De Saint Jean, M., Goguel, A. \& Baudouin, C. Flow cytometric analysis of inflammatory markers in conjunctival epithelial cells of patients with dry eyes. Invest. Ophthalmol. Vis. Sci. 41, 1356-63 (2000)

12. Bourcier, T., De Saint-Jean, M., Brignole, F., Goguel, A. \& Baudouin, C Expression of CD40 and CD40 ligand in the human conjunctival epithelium. Invest. Ophthalmol. Vis. Sci. 41, 120-6 (2000).

13. Giebel, J., Woenckhaus, C., Fabian, M. \& Tost, F. Age-related differential expression of apoptosis-related genes in conjunctival epithelial cells. Acta Ophthalmol. Scand. 83, 471-6 (2005).

14. Khalfaoui, T., Basora, N. \& Ouertani-Meddeb, A. Apoptotic factors (Bcl-2 and Bax) and diabetic retinopathy in type 2 diabetes. J. Mol. Histol. 41, 143-52 (2010). 
15. Tan, D.T., Tang, W.Y., Liu, Y.P., Goh, H.S. \& Smith, D.R. Apoptosis and apoptosis related gene expression in normal conjunctiva and pterygium. Br. J. Ophthalmol. 84, 212-6 (2000).

16. Pellegrini, G. et al. Location and clonal analysis of stem cells and their differentiated progeny in the human ocular surface. J. Cell. Biol. 145, 769-82 (1999).

17. Allansmith, M.R., Greiner, J.V. \& Baird, R.S. Number of inflammatory cells in the normal conjunctiva. Am. J. Ophthalmol. 86, 250-9 (1978).

18. Belfort, R. \& Mendes, N.F. Identification of T and B lymphocytes in the human conjunctiva and lacrimal gland in ocular diseases. Br. J. Ophthalmol. 64, 217-9 (1980).

19. Bhan, A.K., Fujikawa, L.S. \& Foster, C.S. T-cell subsets and Langerhans cells in normal and diseased conjunctiva. Am. J. Ophthalmol. 94, 205-12 (1982).

20. McGhee, J.R., Lamm, M.E. \& Strober, W. Mucosal immune responses. An overview. In Handbook of Mucosal Immunology (Ogra, P.L., Mestecky, J., Lamm, M.E., Strober, W., McGhee, J.R., Bienenstock, J., eds) 485-506 (Academic Press, San Diego, CA, 1999).

21. Hazlett, L.D. Corneal response to Pseudomonas aeruginosa infection. Prog. Retin. Eye Res. 23, 1-30 (2004).

22. Knop, E. \& Knop, N. The role of eye-associated lymphoid tissue in corneal immune protection. J. Anat. 206, 271-85 (2005).

23. Knop, E., Knop, N. \& Claus, P. Local production of secretory IgA in the eye-associated lymphoid tissue (EALT) of the normal human ocular surface. Invest. Ophthalmol. Vis. Sci. 49, 2322-9 (2008).

24. Steven, P. \& Gebert, A. Conjunctiva-associated lymphoid tissue-current knowledge, animal models and experimental prospects. Ophthalmic Res. 42, 2-8 (2009).

25. Hein, W.R. Organization of mucosal lymphoid tissue. In Defense of Mucosal Surfaces: Pathogenesis, Immunity and Vaccines (Kraehenbuhl, J.R., Neutra, M.R., eds) 1-15 (Springer Verlag, Berlin, 1999).

26. Dua, H.S. \& Haynes, R.J. Lymphocyte homing to mucosal surfaces. In Mucosal Immunology and Ocular Disease 1st edn (Forrester, J.V., ed) 93-108 (Aeolus Press, Lisse, 2000).

27. Knop, E. \& Knop, N. Anatomy and immunology of the ocular surface. Chem. Immunol. Allergy 92, 36-49 (2007).

28. Baudouin, C. et al. CCR 4 and CCR 5 expression in conjunctival specimens as differential markers of $T(H) 1 / T(H) 2$ in ocular surface disorders. J. Allergy Clin. Immunol. 116, 614-9 (2005).

29. Reinoso, R. et al. Differential cell proliferation, apoptosis, and immune response in healthy and evaporative-type dry eye conjunctival epithelia. Invest. Ophthalmol. Vis. Sci. 52, 4819-28 (2011).

30. Pflugfelder, S.C., Huang, A.J., Feuer, W., Chuchovski, P.T., Pereira, I.C. \& Tseng, S.C. Conjunctival cytologic features of primary Sjögren's syndrome. Ophthalmology 97, 985-91 (1990).

31. Power, W.J., Mullaney, P., Farrel, M. \& Collum, L.M. Effect of topical cyclosporin A on conjunctival T cells in patients with secondary Sjögren's syndrome. Cornea 12, 507-11 (1993).

32. Stern, M.E. et al. Conjunctival T-cell subpopulations in Sjögren's and nonSjögren's patients with dry eye. Invest. Ophthalmo/ Vis. Sci. 43, 2609-14 (2002).

33. Gulati, A., Sacchetti, M., Bonini, S. \& Dana, R. Chemokine receptor CCR5 expression in conjunctival epithelium of patients with dry eye syndrome. Arch. Ophthalmol. 124, 710-6 (2006).

34. Martínez-Osorio, H. et al. Characterization and short-term culture of cells recovered from human conjunctival epithelium by minimally invasive means. Mol. Vis. 15, 2185-95 (2009).
35. Messmer, E.M., Mackert, M.J., Zapp, D.M. \& Kampik, A. In vivo confocal microscopy of normal conjunctiva and conjunctivitis. Cornea 25, 781-8 (2006).

36. Efron, N., Al-Dossari, M. \& Pritchard, N. In vivo confocal microscopy of the palpebral conjunctiva and tarsal plate. Optom. Vis. Sci. 86, E1303-8 (2009).

37. Barabino, S., Montaldo, E., Solignani, F., Valente, C., Mingari, M.C. \& Rolando, M. Immune response in the conjunctival epithelium of patients with dry eye. Exp. Eye Res. 91, 524-9 (2010).

38. Efron, N., Al-Dossari, M. \& Pritchard, N. In vivo confocal microscopy of the bulbar conjunctiva. Clin. Exp. Ophthalmol. 37, 335-44 (2009).

39. Oduntan, A.O. Cellular inflammatory response induced by sensory denervation of the conjunctiva in monkeys. J. Anat. 206, 287-94 (2005).

40. Qi, H., Zheng, X., Yuan, X., Pflugfelder, S.C. \& Li, D.Q. Potential localization of putative stem/progenitor cells in human bulbar conjunctival epithelium. J. Cell. Physiol. 225, 180-5 (2010).

41. Wei, Z.G., Wu, R.L., Lavker, R.M. \& Sun, T.T. In vitro growth and differentiation of rabbit bulbar, fornix and palpebral conjunctival epithelia Implications on conjunctival epithelial transdifferentiation and stem cells. Invest. Ophthalmol. Vis. Sci. 34, 1814-28 (1993).

42. Wei, Z.G., Cotsarelis, G., Sun, T.T. \& Lavker, R.M. Label-retaining cells are preferentially located in fornical epithelium: implications on conjunctival epithelial homeostasis. Invest. Ophthalmol. Vis. Sci. 36 , 236-46 (1995).

43. Lavker, R.M., Wei, Z.G. \& Sun, T.T. Phorbol ester preferentially stimulates mouse fornical conjunctival and limbal epithelial cells to proliferate in vivo. Invest. Ophthalmol. Vis. Sci. 39, 301-7 (1998).

44. Harun, M.H. et al. Human forniceal region is the stem cell-rich zone of the conjunctival epithelium. Hum. Cell; advance online publication 12 July 2012 (e-pub ahead of print) (2012).

45. Wirtschafter, J.D., Ketcham, J.M., Weinstock, R.J., Tabesh, T. \& McLoon, L.K. Mucocutaneous junction as the major source of replacement palpebral conjunctival epithelial cells. Invest. Ophthalmol. Vis. Sci. 40, 3138-46 (1999).

46. Su, L. et al. Putative rabbit conjunctival epithelial stem/progenitor cells preferentially reside in palpebral conjunctiva. Curr. Eye Res. 36, 797-803 (2011).

47. Chen, W., Ishikawa, M., Yamaki, K. \& Sakuragi, S. Wistar rat palpebral conjunctiva contains more slow-cycling stem cells that have larger proliferative capacity: Implication for conjunctival epithelial homeostasis. Jpn. J. Ophthalmol. 47, 119-28 (2003).

48. Cotsarelis, G., Cheng, S.Z., Dong, G., Sun, T.T. \& Lavker, R.M. Existence of slow-cycling limbal epithelial basal cells that can be preferentially stimulated to proliferate: implications on epithelial stem cells. Cell 57, 201-9 (1989)

49. Lavker, R.M. et al. Hair follicle stem cells: their location, role in hair cycle and involvement in skin tumor formation. J. Invest. Dermatol. 101, 16S-26S (1993).

50. Fujihara, T., Takeuchi, T., Saito, K., Kitajima, Y., Kobayashi, T.K. \& Tsubota, $K$. Evaluation of human conjunctival epithelium by a combination of brush cytology and flow cytometry: an approach to the quantitative technique. Diagn. Cytopathol. 17, 456-60 (1997).

51. Tsubota, K. et al. Regulation of human leukocyte antigen expression in human conjunctival epithelium. Invest. Ophthalmol. Vis. Sci. 40, 28-34 (1999).

52. Wersto, R. et al. Doublet discrimination in DNA cell-cycle analysis. Cytometry. 46, 296-306 (2001). 